PEDAGOGISK FORSKNING I SVERIGE Vol 25 No 4 (2020) ISSN 1401-6788

\title{
Debatt
}

\section{Samverkansprocessens problematik i den praktiknära forskningen}

\author{
Ulf Blossing, professor \\ Institutionen för pedagogik och specialpedagogik, Göteborgs universitet \\ Kontakt: Ulf.blossing@gu.se
}

I den här debattartikeln fokuserar jag kärnan i ULF att ta fram samverkansmodeller som ska präglas av jämlika villkor mellan skola och akademi. De jämlika villkoren är nödvändiga för att skapa delaktighet för samtliga samverkande parter, men det är sällan sådana villkor råder.

Jag fortsätter Serders och Malmströms (2020) problematisering av praktiken och samverkansprocessen, och liksom Persson (2020) frågar jag mig vilka praktiker som forskningen ska vara nära? Problematiseringen sker med utgångspunkt i sociokulturell teoribildning eller praktikteorier (Nicolini, 2013) och mer specifikt tar jag min utgångspunkt i Wengers sociala lärandeteori om praktikgemenskaper (Wenger, 1998; Wenger, FentonO'Creevy, Hutchinson, Kubiak, \& Wenger-Trayner, 2014), praktikarkitekturteorin (Mahon, 2017) och hur meningsskapande sker i sådana praktikgemenskaper (ex. Weick, Sutcliffe, \& Obstfeld, 2005), liksom hur översättning av praktikidéer sker från en praktik till en annan (Lund \& Moksnes Furu, 2014; Røvik, 2016). I min egen forskning har jag deltagit i flera samverkansprojekt varvid jag har haft anledning att reflektera över deras svårigheter och förtjänster (Blossing, Blom, \& Persson, 2016; Blossing \& Liljenberg, 2018). Jag är också ledamot i ULF-rådet vid Karlstads universitet. 
Sammanfattningsvis vill jag med utgångspunkt i den här forskningen påstå att;

- $\quad$ skolor utgör skilda och olika gemenskaper eller praktiker, det vill säga specifika sätt att förstå sin roll, sitt uppdrag och sätt att arbeta,

- förbättringsåtgärder som initieras utifrån en annan praktik översätts till den praktik som råder på en skola och således kan bli en annan åtgärd, bättre eller sämre, än den som initialt presenterades

- forskargemenskaper också är skilda och olika praktiker,

- det inte helt och fullt går att veta eller känna av en praktiks förmågor eller behov om man inte själv är en del av den lokala praktiken,

- detta förhållande utgör en stor svårighet i samverkan mellan praktiker såsom mellan skolor och universitet, det vill säga mellan lärare/skolledare och forskare,

- $\quad$ samverkan kan främjas om parterna har kunskap om på vilket sätt deras respektive praktiker kan skilja sig åt, det vill säga har specifik kunskap om skolkulturer och forskarkulturer samt om hur förhandling och samarbete mellan dem kan ske,

- praktiknära skolforskning endast kan bli praktiknära om lärare/skolledare är delaktiga i forskningen, och att det innebär att forskningen behöver följa delvis andra normer och rutiner än de som gäller för akademiska forskarpraktiker.

De här punkterna betyder, menar jag, att ska vi få till en praktiknära forskning som svarar mot lärares och skolledares behov behöver skolors verksamheter omstruktureras så att undersökande verksamhet ingår som en återkommande rutin $\mathrm{i}$ undervisningen.

Låt oss börja med den första punkten: Vad menas med att skolor kan uppvisa skilda och olika gemenskaper eller praktiker? Praktik är enligt praktikteorier en social verksamhet som utgörs av den verksamhet som skapas av individer $\mathrm{i}$ relation med varandra $\mathrm{i}$ en specifik situation och $\mathrm{i}$ ett lokalt tidsförlopp. Individerna bildar relationer med varandra och samtalar med varandra om hur verksamheten ska genomföras och utvecklas. Det betyder att de ger den en betydelse som har mening för just dem i den situationen och i det tidsförlopp som de tillhör. Vilken betydelse de ger det de utvecklar och vilken mening det kommer att få beror bland annat på den erfarenhet individerna delar med varandra av att tillhöra den gemenskap som hålls samman av ett gemensamt uppdrag.

Lärarna utvecklar en gemensam erfarenhet allteftersom tiden går genom att de hanterar verksamheten. Erfarenheten kommer så småningom att utgöra 
en rik bank av handlingsinriktad kunskap som gemenskapen kan se tillbaka på och använda för att hantera nya situationer. Genom den här processen utvecklar lärarna en kunskap om vad en lärare gör och är på den egna skolan, en identitet. Praktiken blir på det sättet en verksamhet som är införlivad med gemenskapen och identiteten, inte något som är skilt från gemenskapen och som lärarna kan ha distans till utan som de är mer eller mindre ett med. Distans till den egna praktiken kan utvecklas med åren om läraren kanske byter arbetsplats, det kommer nya medarbetare till skolan eller läraren tillägnar sig kunskap om hur skolor kan uppvisa olika kulturer.

Vad det innebär att vara lärare, att undervisa och bedöma elevernas lärande, att utveckla och förbättra på just den skola där lärarna arbetar är något som endast de som är en del av den lokala praktiken kan veta. Finns det då inte någon generell kunskap? Jo, lärare och skolledare delar en rad strukturer för verksamheten, en praktikarkitektur, som gäller lika för dem alla, vilket gör att på en mer övergripande nivå finns generella villkor och således kunskap att nyttja. Men den kunskapen behöver översättas till den lokala och specifika praktiken för att bli användbar, och då behöver översättare finnas tillgängliga på skolan. Dessa översättare har kunskap om hur olika praktiker kan se ut och har övat upp en förmåga att greppa det meningsskapande som äger rum i den specifika praktiken.

När en samverkansprocess mellan två skilda praktiker ska fås att fungera såsom i ULF-försöket, behöver översättare finnas med i arbetet. Wenger (1998) beskriver hur mötet mellan olika praktiker kan ge upphov till spänningar som å ena sidan leder till motsättningar som kan få samverkansprocessen att stanna upp eller att en av parterna viker sig för den andra parten. Men spänningarna kan i bästa fall leda till en kreativ process som inte någon av parterna skulle kunna ha åstadkommit på egen hand. Jag har dokumenterat den här processen i ett av de samverkansprojekt jag själv har genomfört (Blossing m.fl., 2016) och mina kollegor i forskningsmiljön Skolutveckling och ledarskap vid Göteborgs universitet har en rad andra exempel (ex. Liljenberg \& Nyman Alm, 2020; Olin, 2019).

Samverkansprocessen kompliceras av att en skolpraktik inte endast utgörs av lärarna och deras undervisning utan är sammankopplad med ledarpraktiken som utgörs av rektorer och mellanledare som förstelärare, arbetslagsledare, processledare etc. I dag finns ett fokus mot lärarnas undervisning i såväl Skolforskningsinstitutets satsningar som ULFs försöksverksamhet. Och det är bra då forskning har visat att det inte alltid har varit tydligt i skolors förbättringsarbeten. Men det blir till en nackdel när det resulterar i att forskningen fokuserar lärarna på ett sätt som inte tar hänsyn till den praktik de är en del av på sin skola. Rektors och mellanledares ledarskap, och ansvar, för verksamheten är en integrerad del av lärarnas arbete och undervisning. Det är således "skolan" och dess praktik som utgör samverkansobjektet för akademins forskare och inte endast lärargruppen. 
Dessutom är huvudmannens förvaltning eller branschorganisation en integrerad del som behöver förstås och tas med i förhandlingen.

Utifrån den forskning jag här har gjort ett utsnitt utav och från vad jag hittills erfarit kommer ULF inte att resultera i att samverkansmodeller uppstår som ger jämlika villkor där lärare och skolledare är delaktiga på riktigt. Det är snararare så att akademins forskare genom ULF kommer att få tillgång till ytterligare en forskningsfinansiär. Det är det som kommer att bli huvudresultatet, inte att forskningen blir praktiknära och en verksamhet för alla lärare och deras undervisning så att Sveriges skolor blir bättre för elevernas lärande.

\section{REFERENSER}

Blossing, Ulf, Blom, Ann, \& Persson, Karin (2016). Att skapa en samverkansprocess - en forskare och två verksamhetschefer i partnerskap. I K. Rönnerman, A. Olin, E. Moksnes Furu, \& A.-C. Wennergren (red.), Fångad av praktiken: skolutveckling genom partnerskap (Vol. 11, s. 199-216). Göteborg: Rapporter från Institutionen för pedagogik och specialpedagogik.

Blossing, Ulf, \& Liljenberg, Mette(2018). Partssamarbete med aktionsforskning för att förbättra skolledares ledarbandlingar. Hämtad från http:// hdl.handle.net/2077/56145

Liljenberg, Mette, \& Nyman Alm, Annica (2020). Att samverka i samverkan. I A. Olin \& Å. Hirsh (red.), Samverkan genom uppdrag. Lärdomar för universitetet och samverkande partners $i$ utbildnings- och forskningsuppdrag (Vol. 18, s. 10-28). Göteborg: Rapporter från Institutionen för pedagogik och specialpedagogik. Hämtad från http://hdl.handle.net/2077/63225.

Lund, Torbjørn, \& Moksnes Furu, Eli (2014). Action research and translation studies. Understanding the change of practice. In K. Rönnerman \& P. Salo (red.), Lost in Practice: Transforming Nordic Educational Action Research (s. 31-52). Rotterdam: Sense Publishers.

Mahon, Kathleen, Francisco, Susanne, \& Kemmis, Stephen (red.) (2017). Exploring Education and Professional Practice: Through the Lens of Practice Architectures. Singapore: Springer Singapore.

Nicolini, Davide (2013). Practice theory, work, and organization: an introduction. Oxford: Oxford University Press.

Olin, Anette (2019). Samarbete i praktiknära forskning. I I. Henning Loeb, L. Langelotz, \& K. Rönnerman (red.), Att utveckla utbildningspraktiker. Analys, förståelse och förändring genom teorin om praktikarkitekturer (s. 137-162). Lund: Studentlitteratur.

Persson, Anders (2020). Dubbel närhet och distans behövs inom praktiknära forskning. Pedagogisk forskning i Sverige, Ahead of print.

https://open.lnu.se/index.php/PFS/article/view/2547 
Røvik, Kjell A. (2016). Knowledge Transfer as Translation: Review and Elements of an Instrumental Theory. International Journal of Management Reviews, 18(3), 290-310. doi:10.1111/ijmr.12097

Serder, Margareta, \& Malmström, M. (2020). Vad talar vi om när vi talar om praktiknära forskning? Pedagogisk forskning i Sverige, 25(1), 107-109. . doi:https://doi.org/10.15626/pfs25.01.07

Weick, Karl E., Sutcliffe, Kathleen M., \& Obstfeld, David (2005). Organizing and the Process of Sensemaking. Organization Science, 16(4), 409-421.

Wenger, Etienne (1998). Communities of practice: learning, meaning, and identity.

Cambridge: Cambridge University Press.

Wenger, Etienne, Fenton-O'Creevy, Mark, Hutchinson, Steven, Kubiak, Chris, \& Wenger-Trayner, Beverly (2014). Learning in landscapes of practice: boundaries, identity, and knowledgeability in practice-based learning. Abingdon: Routledge. 